OPEN ACCESS

Edited by:

Penghua Wang,

University of Connecticut Health

Center, United States

Reviewed by:

Daxing Gao,

The Rockefeller University,

United States

Noemi Sevilla,

Instituto Nacional de Investigación y

Tecnología Agraria y Alimentaria (INIA), Spain

*Correspondence: Haixue Zheng

haixuezheng@163.com

${ }^{\dagger}$ These authors have contributed equally to this work

Specialty section: This article was submitted to

Virology,

a section of the journal

Frontiers in Microbiology

Received: 25 April 2018 Accepted: 11 September 2018 Published: 27 September 2018

Citation:

Zhu Z, Du X, Li P, Zhang X, Yang F, Cao W, Tian H, Zhang K, Liu X and

Zheng H (2018) Early Growth Response Gene-1 Suppresses Foot-and-Mouth Disease Virus Replication by Enhancing Type I Interferon Pathway Signa Transduction

Front. Microbiol. 9:2326. doi: 10.3389/fmicb.2018.02326

\section{Early Growth Response Gene-1 Suppresses Foot-and-Mouth Disease Virus Replication by Enhancing Type I Interferon Pathway Signal Transduction}

\author{
Zixiang Zhu', Xiaoli Du', Pengfei Li, Xiangle Zhang, Fan Yang, Weijun Cao, Hong Tian, \\ Keshan Zhang, Xiangtao Liu and Haixue Zheng*
}

State Key Laboratory of Veterinary Etiological Biology, National Foot and Mouth Diseases Reference Laboratory, Key Laboratory of Animal Virology of Ministry of Agriculture, Lanzhou Veterinary Research Institute, Chinese Academy of Agricultural Sciences, Lanzhou, China

Early growth response gene-1 (EGR1) is a multifunctional transcription factor that is implicated in viral infection. In this study, we observed that foot-and-mouth disease virus (FMDV) infection significantly triggered EGR1 expression. Overexpression of EGR1 suppressed FMDV replication in porcine cells, and knockdown of EGR1 considerably promoted FMDV replication. A previously reported FMDV mutant virus (with two amino acids mutations in SAP domain) that displays a strong type I interferon (IFN) induction activity was used in this study. We found that SAP mutant FMDV infection induced a higher expression of EGR1 than wildtype FMDV infection, and also triggered higher IFN$\beta$ and IFN-stimulated genes (ISGs) expression than wildtype FMDV infection. This implied a link between EGR1 and type I IFN signaling. Further study showed that overexpression of EGR1 resulted in Sendai virus (SeV)-induced IFN-stimulated response element (ISRE) and NF-kB promoter activation. In addition, the SeV-induced ISGs expression was impaired in EGR1 knockdown cells. EGR1 upregulation promoted type I IFN signaling activation and suppressed FMDV and Seneca Valley virus replication. Suppression of the transcriptional activity of EGR1 did not affect its antiviral effect against FMDV. This study reveals a new mechanism evolved by EGR1 to enhance type I IFN signaling and suppress FMDV replication.

Keywords: foot-and-mouth disease virus, early growth response gene-1, interferon, viral replication, antiviral response

\section{INTRODUCTION}

Foot-and-mouth disease virus (FMDV) is a non-enveloped virus with positive-sense and singlestranded RNA genome. The viral genome is approximately $8.5 \mathrm{~kb}$ nucleotides in length, including a single large open reading frame that encodes a polyprotein. The polyprotein is subsequently processed by viral proteases during protein synthesis, generating several intermediates and 12 mature proteins (Sobrino and Domingo, 2001; Grubman and Baxt, 2004). During co-evolution with the hosts, these viral proteins have acquired many functions to counteract host antiviral 
responses, cause immunosuppression, and promote viral replication and infection (Mason et al., 2003; Rodriguez Pulido and Saiz, 2017). Therefore, FMDV causes an acute vesicular disease of infected animals, which is called foot-and-mouth disease (FMD). FMD is a highly contagious disease that can lead to significant economic losses to the local livestock industry (Rweyemamu et al., 2008a; Paton and Taylor, 2011; Zai-Xin, 2015; Bouguedour and Ripani, 2016). The understanding of host-FMDV interaction as well as the involved mechanism contributes to the planning of new strategies for FMD prevention (Domingo et al., 2005; Rweyemamu et al., 2008b; Rodriguez Pulido and Saiz, 2017). Accordingly, many researches on host responses in FMDV-infected cells have to be investigated.

Early growth response gene-1 (EGR1), also designated zif268, is a host transcriptional regulator that expresses rapidly after a number of stimuli like oxygen deprivation, growth factors, cytokines, shear stress and injury (Brand et al., 1992; Khachigian et al., 1997; Nishi et al., 2002; Jo et al., 2011; Li et al., 2013). EGR1 is involved in diverse biologic functions and a broad variety of host signal transduction cascades that mediates cell growth, survival, differentiation, apoptosis and proliferation (Pagel and Deindl, 2011; Papanikolaou et al., 2014). Different pathways have been identified that participate in EGR1 induction and then regulates several biological behaviors. Such as, the Ras homologue gene family (Rho) genes are involved in cell cycle progression, and the Rho/Rho-kinase pathway has been shown to regulate EGR1 expression (Barrientos et al., 2007; Pagel and Deindl, 2011). As a zinc-finger DNA-binding protein, EGR1 also regulates expression of diverse gene families by binding to promoter sequences of target genes (Papanikolaou et al., 2014). Therefore, EGR1 is involved in activation of signal transduction of many pathways.

Several studies indicate that EGR1 is linked to viral infection and immune response. EGR1 modulates pro-apoptotic pathway and promotes Venezuelan equine encephalitis virus (VEEV) replication (Baer et al., 2016). Knockdown of EGR1 in Rhabdomyosarcoma cells decreases enterovirus 71 (EV71) replication (Song et al., 2015). It seems that EGR1 might play a positive role in these viruses replication. However, EGR1 also appears critical for the initiation of immune response in B cells and $\mathrm{T}$ cells. EGR1 plays roles in regulation of the expression of sever cytokines including interleukin-2, CD44, ICAM-1 and tumor necrosis factor genes (Skerka et al., 1995; McMahon and Monroe, 1996; Shin et al., 2009; Cubero and Nieto, 2012).

An SAP domain [scaffold-attachment factor (SAF)-A/B, apoptotic chromatin-condensation inducer in the nucleus (ACINUS) and PIAS (protein inhibitor of activated signal transducer and activator of transcription) domain] previously was identified within the FMDV $\mathrm{L}^{\text {pro }}$ by de los Santos et al. (2009). Mutation of $L^{\text {pro }}$ SAP domain promotes type I IFN signaling activation and decreases virus growth. In addition, animals inoculated with the FMDV SAP mutant display strong neutralizing antibody response and $\mathrm{T}$ cell response comparing with infection with wildtype FMDV (de los Santos et al., 2009; Diaz-San Segundo et al., 2012). In this study, a robust EGR1 upregulation was observed in both wildtype and SAP mutant FMDV-infected cells comparing with the mock-infected cells by viewing the protein abundance of EGR1. Therefore, we investigated the correlation between FMDV infection and EGR1, and determined the antiviral role of EGR1 against FMDV. SAP mutant FMDV infection induced a higher expression of EGR1 than wildtype FMDV infection. SAP mutant FMDV infection also triggered higher IFN- $\beta$ and IFN-stimulated genes (ISGs) expression than wildtype FMDV infection. We also found that overexpression of EGR1 enhanced Sendai virus (SeV)-induced interferon (IFN)-stimulated response element (ISRE) activation. $\mathrm{SeV}$-induced ISGs expression was impaired in EGR1 knockdown cells, which may serve as a link between upregulation of EGR1 and type I IFN signaling. Further study showed that EGR1 enhanced TBK1 phosphorylation during FMDV infection. It indicated that EGR1 upregulation promoted type I IFN signaling activation by enhancing TBK1 phosphorylation and resulted in decreased FMDV replication. This study reveals a link between EGR1 and innate immune response during FMDV infection.

\section{MATERIALS AND METHODS}

\section{Cell Lines, Viruses and Reagents}

Porcine kidney PK-15 cells, human embryonic kidney 293T cells (HEK293T) cells described previously (Zhu et al., 2016) were maintained in Dulbecco's modified Eagle's medium supplemented with $10 \%$ heat-inactivated fetal bovine serum, $100 \mathrm{U} / \mathrm{ml}$ penicillin, and $100 \mu \mathrm{g} / \mathrm{ml}$ streptomycin sulfate. All the cells were cultured at $37^{\circ} \mathrm{C}$ under $5 \% \mathrm{CO} 2$. Sendai virus (SeV), a model RNA virus widely used to activate type I IFN signaling in cells, was kindly provide by Hongbing Shu's Laboratory (Wuhan University, China) (Zhou et al., 2014; Li D. et al., 2016). FMDV strain O/BY/CHA/2010 (GenBank number: JN998085) described previously was used for virus infection (Zheng et al., 2012).

Commercial antibodies used in this study include an anti-EGR1 mouse monoclonal antibody (Abcam, Cambridge, MA, United States), anti-TBK1 rabbit antibody from Cell Signaling Technology (CST) Inc. (Beverly, MA, United States), anti-phospho-TBK1 rabbit antibody (CST), anti-c-Myc mouse antibody (Santa Cruz Biotechnology, Santa Cruz, CA, United States) and anti- $\beta$-actin mouse antibody (Santa Cruz Biotechnology). Anti-IFN- $\beta$ and anti-IFN- $\alpha$ antibodies (5000 NU/ml, PBL Biomedical Laboratories) and IgG isotype antibodies were used in the type I IFN-blocking experiments as previously described (Trottier et al., 2009). Anti-FMDV VP1 protein polyclonal antibody was previously produced in our laboratory (Zhu et al., 2016). Transfection reagents include OPTI-MEM medium and the Lipofectamine 2000 that were purchased from Invitrogen. Poly (I:C) was purchased from InvivoGen. IFN- $\beta$ was purchased from PBL Biomedical Laboratories.

\section{Plasmids and Transfection}

The full-length porcine EGR1 cDNA fragment was cloned into

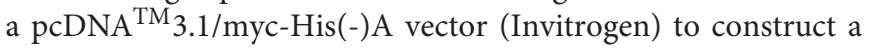
Myc-tagged EGR1 eukaryotic expressing plasmid (Myc-EGR1, including a C-terminal Myc tag). The constructed plasmid was 
analyzed and verified by DNA sequencing. A series of plasmids expressing HA-tagged type I IFN pathway-related proteins [including MDA5, RIG-I(CARD), VISA, TBK1, IRF3 and IRF7], and the IFN- $\beta$ promoter luciferase reporter plasmids and control plasmid Renilla luciferase pRL-TK were kindly provided by Hongbing Shu's Laboratory (Zhou et al., 2014; Li D. et al., 2016). The plasmids were transfected into cells using OPTIMEM medium and the Lipofectamine 2000 (Invitrogen) reagent according to the manufacture's protocol.

\section{Real-Time Quantitative PCR (qPCR)}

TRIzol reagent (Invitrogen) was used to extract cellular or viral RNA following the instruction of the protocol. The firststrand cDNA was synthesized by reverse transcription reaction with the extracted RNAs as templates. Reverse transcription was performed with M-MLV reverse transcriptase (Invitrogen) and random hexamer primers (TaKaRa) according to the manufacturer's recommendations. The quantification of the cDNA was performed by $\mathrm{qPCR}$. The relative amounts of the synthesized cDNA was determined as an indicator of the target transcripts. qPCR was carried out using SYBR Premix Ex Taq (Takara) on a QuantStudio 5 Real-Time PCR instrument (Applied Biosystems) according to the manufacturer's instructions. The glyceraldehyde-3-phosphate dehydrogenase (GAPDH) gene was used for normalization in qPCR analysis. Relative transcript levels were calculated using $2^{-\Delta \Delta C T}$ method as described previously (Zhu et al., 2016). All the primers used in this study were listed in Table $\mathbf{1 .}$

\section{Immunoblotting Analysis}

For Western blotting, the cells were collected at the indicated time points and. The lysed cell extracts were resolved by $10 \%$ SDSPAGE and transferred onto a nitrocellulose membrane (Pall). The nitrocellulose membrane was then blocked with $10 \%$ skim milk powder in TBST (20 mM Tris, $55 \mathrm{mM} \mathrm{NaCl}, 0.1 \%$ Tween 20) overnight at $4^{\circ} \mathrm{C}$. The membrane was incubated with primary and secondary antibodies as described previously (Zhu et al., 2013). The membrane was washed $3 \times 5 \mathrm{~min}$, before being protein abundance analysis. The antibody-antigen complexes were visualized using enhanced chemiluminescence detection reagents (Thermo).

\section{RNA Interference (RNAi)}

Small interfering RNA (siRNA) was used to knockdown EGR1 protein expression. siRNA fragments were chemically synthesized by genepharma company (China). The sequences of the siRNAs used in this study include: 5'-CCAUGGA CAACUACCCUAATT-3' (EGR siRNA-353), 5' -GCCUAGUGA GCAUGACCAATT-3' (EGR siRNA-749), and 5'-GCUGUCA CCAACUCCUUCATT-3' (EGR siRNA-1819). A non-targeting siRNA (NC siRNA) was used as a negative control. siRNA fragments were transfected into cells using Lipofectamine 2000 as described previously (Li W. et al., 2016). Forty-eight hours after siRNA transfection, cells were used for further experiments. To examine the effect of siRNA on EGR1 expression, EGR1 mRNA and protein abundance were measured by qPCR and Western blotting respectively.
TABLE 1 | The primers used in this study.

\begin{tabular}{|c|c|c|}
\hline Gene & Primers $\left(5^{\prime} \rightarrow 3^{\prime}\right)$ & Application \\
\hline \multirow[t]{2}{*}{ Porcine-EGR1 } & $\begin{array}{l}\text { Forward: } \\
\text { TTATCTCGAGATGGCGGCAGCCAA }\end{array}$ & RT-PCR \\
\hline & $\begin{array}{l}\text { Reverse: } \\
\text { GCAAGCTTGCAGATTTCAATTGTCC } \\
\text { TGGGAGA }\end{array}$ & \\
\hline \multirow[t]{2}{*}{ FMDV } & $\begin{array}{l}\text { Forward: } \\
\text { CACTGGTGACAGGCTAAGG }\end{array}$ & qPCR \\
\hline & $\begin{array}{l}\text { Reverse: } \\
\text { CCCTTCTCAGATTCCGAGT }\end{array}$ & \\
\hline \multirow[t]{2}{*}{ P/H-GAPDH } & $\begin{array}{l}\text { Forward: } \\
\text { ACATGGCCTCCAAGGAGTAAGA }\end{array}$ & qPCR \\
\hline & $\begin{array}{l}\text { Reverse: } \\
\text { GATCGAGTTGGGGCTGTGACT }\end{array}$ & \\
\hline \multirow[t]{2}{*}{ P/H-EGR1 } & $\begin{array}{l}\text { Forward: } \\
\text { GACCACCTCACCACCCACAT }\end{array}$ & qPCR \\
\hline & $\begin{array}{l}\text { Reverse: } \\
\text { CCGCAAGTGGATCTTGGTAT }\end{array}$ & \\
\hline \multirow[t]{2}{*}{ Porcine-IFN- $\beta$} & $\begin{array}{l}\text { Forward: } \\
\text { GCTAACAAGTGCATCCTCCAAA }\end{array}$ & qPCR \\
\hline & $\begin{array}{l}\text { Reverse: } \\
\text { AGCACATCATAGCTCATGGAAAGA }\end{array}$ & \\
\hline \multirow[t]{2}{*}{ Porcine-MX1 } & $\begin{array}{l}\text { Forward: } \\
\text { GAGGTGGACCCCGAAGGA }\end{array}$ & qPCR \\
\hline & $\begin{array}{l}\text { Reverse: } \\
\text { CACCAGATCCGGCTTCGT }\end{array}$ & \\
\hline \multirow[t]{2}{*}{ Porcine-ISG15 } & $\begin{array}{l}\text { Forward: } \\
\text { GATCGGTGTGCCTGCCTTC }\end{array}$ & qPCR \\
\hline & $\begin{array}{l}\text { Reverse: } \\
\text { CGTTGCTGCGACCCTTGT }\end{array}$ & \\
\hline \multirow[t]{2}{*}{ Human-IFN- $\beta$} & $\begin{array}{l}\text { Forward: } \\
\text { GACATCCCTGAGGAGATTAAG }\end{array}$ & qPCR \\
\hline & $\begin{array}{l}\text { Reverse: } \\
\text { ATGTTCTGGAGCATCTCATAG }\end{array}$ & \\
\hline \multirow[t]{2}{*}{ Human-ISG15 } & $\begin{array}{l}\text { Forward: } \\
\text { TGGACAAATGCGACGAACC }\end{array}$ & qPCR \\
\hline & $\begin{array}{l}\text { Reverse: } \\
\text { CCCGCTCACTTGCTGCTT }\end{array}$ & \\
\hline \multirow[t]{2}{*}{ Human-MX1 } & $\begin{array}{l}\text { Forward: } \\
\text { ACCTCGTGTTCCAACTGAAG }\end{array}$ & qPCR \\
\hline & $\begin{array}{l}\text { Reverse: } \\
\text { GTGTGATGAGCTCGCTGGTA }\end{array}$ & \\
\hline
\end{tabular}

\section{Dual Luciferase Reporter Assays}

HEK293T cells seeded on 24-well plates were co-transfected with $100 \mathrm{ng}$ luciferase reporter plasmid with $10 \mathrm{ng}$ internal control Renilla luciferase reporter plasmid (to normalize for transfection efficiency) PRL-TK (Promega), together with the indicated plasmids and/or empty vector controls using Lipofectamine 2000 according to the manufacture's instruction. To make the cells receive the same amounts of total plasmids, the empty vector plasmids were used in all transfection experiments. As for $\mathrm{SeV}$ mediated type I IFN signaling pathway activation, the cells were mock-infected or infected with $\mathrm{SeV}$ (100HAU/mL) for $16 \mathrm{~h}$; and the dual luciferase assays were then performed according to the Promega Dual-Luciferase Reporter Assay System protocol. The relative luciferase activity was expressed as arbitrary units by normalizing firefly to Renilla luciferase activity. As for type I 
IFN pathway adaptor molecules-induced IFN-element activation assay, the HEK293T cells were co-transfected with the reporter plasmids with the indicated plasmid or vector plasmid for $24 \mathrm{~h}$; and the luciferase activities were measured.

\section{Statistical Methods}

All experiments were performed at least in triplicate. The measured values are represented as mean \pm SD from three independent experiments. The statistical significance analyses were performed using the Student's $t$-test. Data considered significant when ${ }^{*} P<0.05$, and highly significant when ** $P<0.01$.

\section{RESULTS}

\section{FMDV Infection Upregulates EGR1 Expression}

PK-15 cells were infected by equal amounts of wildtype or SAP mutant FMDV for $12 \mathrm{~h}$ as previously described (Zhu et al., 2015). The expression levels of EGR1 and viral VP1 protein were detected by Western blotting. We observed that EGR1 protein level is significantly upregulated both in wildtype and SAP mutant FMDV-infected cells at $12 \mathrm{~h}$ postinfection (hpi) (Figure 1A). Therefore, the correlation between FMDV infection and EGR1 was further investigated. The dynamics of EGR1 in FMDV-infected cells were determined. Transcripts of EGR1 were considerably upregulated after FMDV infection and reached to the highest level at $8 \mathrm{hpi}$. No significant changes were observed in mock-infected cells (Figure 1B). EGR1 protein expression was also gradually upregulated as the infection progressed (Figure 1C). This indicates that FMDV infection triggers upregulation of EGR1. To investigate whether EGR1 is an IFN inducible gene, HEK293T and PK-15 cells were incubated with IFN- $\beta$ to induce the expression of IFN inducible genes. The expression of two IFN inducible genes ISG15 and ISG54 was highly induced by incubation of IFN- $\beta$. However, the expression of EGR1 was not changed by treatment of IFN- $\beta$ (Figure 1D). This indicated that EGR1 expression was not induced by IFN$\beta$ treatment; however, FMDV infection could induce EGR1 expression.

\section{EGR1 Plays an Anti-viral Role During FMDV Replication}

To investigate the potential role of EGR1 during FMDV infection, we evaluated the viral replication level in EGR1 overexpressed cells. PK-15 cells were transfected with different doses of EGR1 expressing plasmids, the cells were incubated with equal amounts of FMDV (0.5 MOI) at $24 \mathrm{~h}$ post-transfection (hpt). The viral protein and viral RNA expression level was measured at $12 \mathrm{hpi}$. Overexpression of EGR1 significantly suppressed both the viral protein expression and viral RNA replication. The viral titers in both vector and EGR1 plasmids $(2 \mu \mathrm{g})$ transfected cells were measured and compared, which showed that FMDV yields were also decreased by overexpression of EGR1 (Figure 2A). To further confirm the antiviral role of EGR1 during FMDV infection, the siRNAs that target EGR1 were designed and evaluated. PK-15 cells were transfected with the NC siRNA or EGR1 siRNA for $48 \mathrm{~h}$, the interference efficacy of the siRNAs was determined by qPCR analysis. The EGR1 siRNA-1819 showed the highest efficacy and was used for EGR1 knockdown assay (Figure 2B). PK-15 cells were transfected with EGR1 siRNA1819, the cells were infected with FMDV at $48 \mathrm{hpt}$ and incubated for another 12 or $16 \mathrm{~h}$. The expression of EGR1 and FMDV VP1 protein was detected using Western blotting. Knockdown of EGR1 considerably increased VP1 protein expression during FMDV infection (Figure 2C). The relative fold-change in abundance of FMDV VP1 protein in FMDV-infected NC siRNA or EGR1 siRNA cells was determined by densitometric analysis and normalized to $\beta$-actin, which confirmed that knockdown of EGR1 enhanced FMDV VP1 protein expression (Figure 2C, right panel). Viral RNA detection also suggested that knockdown of EGR1 promoted viral replication (Figure 2D). The viral titers were subsequently measured at $16 \mathrm{hpi}$, which showed that knockdown of EGR1 significantly promoted FMDV propagation (Figure 2D, right panel). These results suggest the antiviral role of EGR1 against FMDV.

\section{EGR1 Enhances Type I IFN Signaling}

Both wildtype and SAP mutant FMDV infection resulted in EGR1 upregulation, however, SAP mutant FMDV resulted in a higher upregulation of EGR1 (Figure 1A). Previous study indicates SAP mutant FMDV infection induces higher expression of IFN- $\beta$ and ISGs than wildtype FMDV infection (de los Santos et al., 2009). We also investigated the expression state of IFN- $\beta$ and ISGs (ISG15 and MX1) in the cells infected by wildtype or SAP mutant FMDV. At 12 hpi, there was $\sim 3$-fold difference in IFN- $\beta$ transcripts for SAP mutant FMDV-infected cells relative to wildtype FMDV-infected cells (Figure 3A). A similar pattern was observed for ISG15 and MX1, varying from 2- to 4-fold higher for SAP mutant FMDV compared to wildtype FMDV (Figure 3A). These results were similar to the previous results reported by de los Santos et al. (2009). This showed that both EGR1 expression and type I IFN signaling were enhanced in SAP mutant FMDVinfected cells. This implied a link between EGR1 and type I IFN pathway.

To identify the role of EGR1 on type I IFN signaling, EGR1 is overexpressed in HEK293T cells, and the $\mathrm{SeV}$ that is routinely used to induce type I IFNs in cell culture was used to activate type I IFN signaling. Overexpression of EGR1 significantly promoted $\mathrm{SeV}$-induced type I IFN signaling, showing a dosedependent manner (Figure 3B). The expression of IFN- $\beta$, ISG15 and MX1 in EGR1 overexpressed cells were subsequently evaluated. The results showed that overexpression of EGR1 considerably promoted SeV-induced IFN- $\beta$, ISG15 and MX1 expression (Figure 3C). The effect of EGR1 on SeV-induced NF- $\kappa \mathrm{B}$ activation was also evaluated by dual luciferase reporter assay, which also showed that EGR1 positively enhanced NF$\kappa \mathrm{B}$-mediated transcriptional activity (Figure $3 \mathrm{D}$ ). The role of EGR1 on Poly (I:C)-induced type I IFN signaling was further evaluated. Overexpression of EGR1 significantly promoted Poly (I:C)-induced type I IFN signaling (Figure 3E). The expression of Poly (I:C)-induced ISGs was also measured. The results 
A

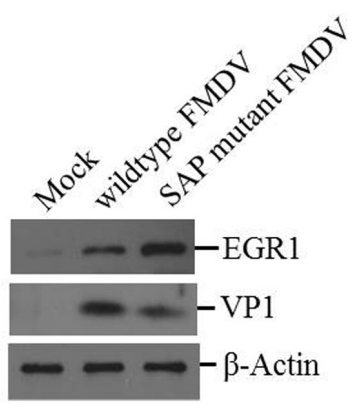

C

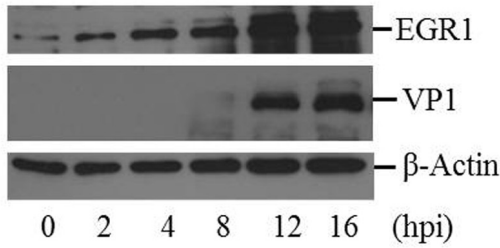

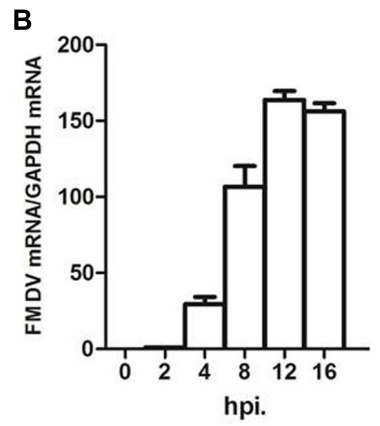

D

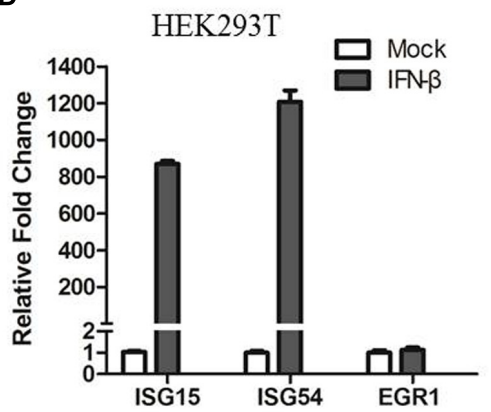

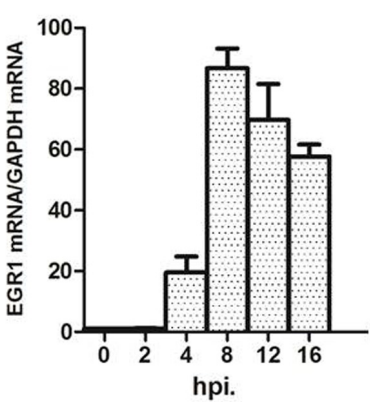

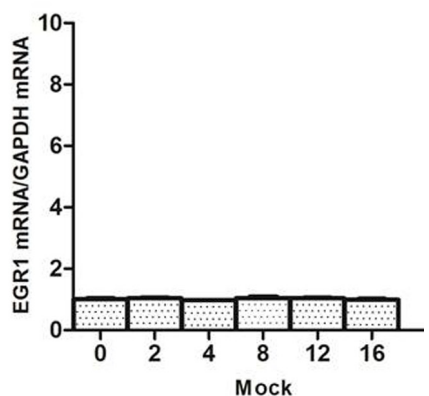

PK-15

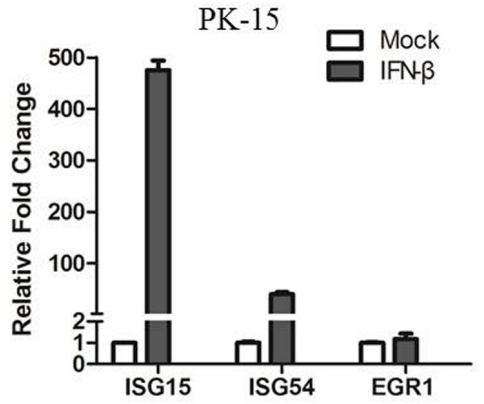

FIGURE 1 | State of EGR1 in FMDV-infected cells. (A) PK-15 cells were incubated with equal amounts of SAP mutant FMDV or wildtype FMDV for $12 \mathrm{~h}$, the abundance of EGR1 and viral VP1 protein was detected. (B) PK-15 cells were infected with wildtype FMDV or mock-infected for 0, 2, 4, 8, 12, or 16 h. The transcripts of EGR1 and viral RNA were detected by qPCR. (C) PK-15 cells were infected with wildtype FMDV for 0, 2, 4, 8, 12 , or $16 \mathrm{~h}$. The expression levels of EGR1 and VP1 protein were detected by Western blotting. (D) HEK293T or PK-15 cells were mock-treated or incubated with IFN- $\beta$ at a concentration of $10 \mathrm{ng} / \mathrm{ml}$ for $12 \mathrm{~h}$. The expression levels of ISG15, ISG54 and EGR1 was measured by qPCR.

showed that overexpression of EGR1 considerably promoted Poly (I:C)-induced ISG15 and ISG54 expression (Figure 3F). SeVinduced ISGs expression levels in EGR1 knockdown cells were also analyzed. The siRNA interference efficacy was also verified in HEK293T cells (Figure 3G). EGR1 was knocked down by transfection of siRNA, and the cells were infected by $\mathrm{SeV}$ at 48 $\mathrm{hpt}$ and incubated for $16 \mathrm{~h}$. The expression of IFN- $\beta$, ISG15 and MX1 were measured. The transcript levels of IFN- $\beta$, ISG15 and MX1 remarkably decreased in EGR1 knockdown cells comparing with that in NC siRNA cell (Figure 3H). These results suggested a positive regulatory role of EGR1 on type I IFN signaling.

The type I IFN blocking antibody experiments were also performed. Anti-IFN- $\beta$ and anti-IFN- $\alpha$ antibodies $(5000 \mathrm{NU} / \mathrm{ml})$ was used to block type I IFN signaling in PK-15 cells, the EGR1overexpressed cells were treated with IFN antibodies for $1 \mathrm{~h}$ and then infected with FMDV. The viral yields were measured at
12 hpi. Type I IFN blocking antibodies obviously abrogated the inhibitory effects of EGR1 on FMDV propagation (Figure 3I). These results suggested that EGR1 suppressed FMDV replication by enhancing type I IFN signaling. We also evaluated the antiviral role of EGR1 against another picornavirus Seneca Valley Virus (SVV) which showed a close relationship with FMDV, and we found that upregulation of EGR1 also enhanced ISGs expression (ISG15 and ISG54) and suppressed SVV replication (Figure 3J).

\section{EGR1 Enhanced the Activation of the ISRE Luciferase Reporter Stimulated by TBK1 or Its Upstream Molecules (RIG-I, MDA5 and VISA)}

EGR1 enhanced type I IFN signaling. This raised the possibility that EGR1 targeted one or several adaptor proteins of the type 
A

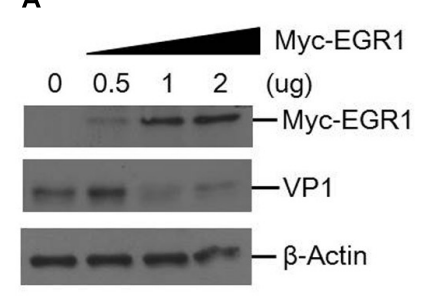

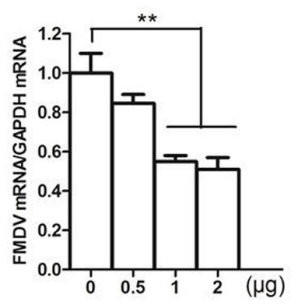

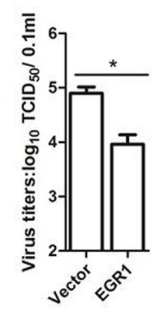

B
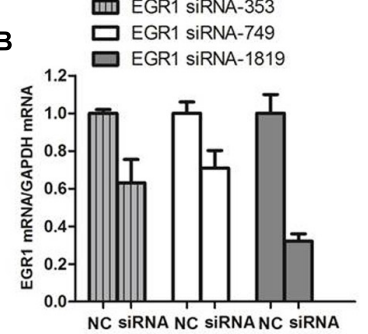

c

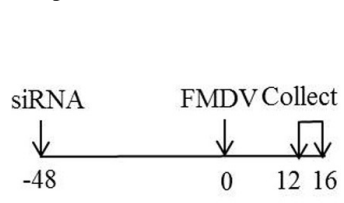

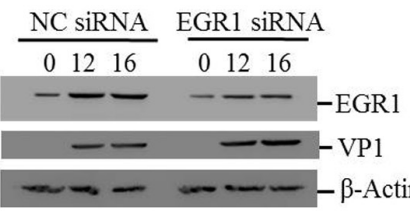
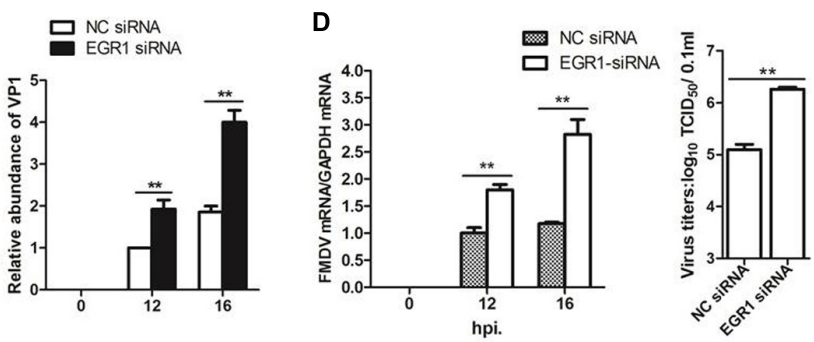

FIGURE 2 | Antiviral effect of EGR1 against FMDV. (A) PK-15 cells were transfected with 0, 0.5, 1, or $2 \mu \mathrm{g}$ of Myc-EGR1, the empty vector plasmids were used in all transfection experiments to ensure the cells receive the same amounts of plasmids. The cells were infected with $0.5 \mathrm{MOI}$ of FMDV at $24 \mathrm{hpt}$ and incubated for another $12 \mathrm{~h}$. The viral protein and RNA were detected. The viral titers in the vector and EGR1 plasmids $(2 \mu \mathrm{g})$ transfected cells were measured by TCID 50 assay. (B) PK-15 cells were transfected with NC (negative control) or siRNA (EGR1 siRNA-353, EGR1 siRNA-749 or EGR1 siRNA-1819) for $48 \mathrm{~h}$. The EGR1 mRNA levels were measured by qPCR. (C) Schematic diagram of the strategy in EGR1 knockdown experiment and investigation of the viral replication state in EGR1 knockdown cells. PK-15 cells were transfected with NC siRNA or EGR1 siRNA-1819 for $48 \mathrm{~h}$. The cells were infected with FMDV for 0, 12, or $16 \mathrm{~h}$. Viral protein abundance was measured by Western blotting. Relative fold-change in abundance of VP1 protein was determined by densitometric analysis using Quantity One software (Bio- Rad) and normalized to $\beta$-actin. (D) Viral RNA levels in FMDV-infected NC siRNA or EGR1 siRNA-1819 cells at 0, 12, and 16 hpi were measured by qPCR. Viral yields in FMDV-infected NC siRNA or EGR1 siRNA-1819 cells at 16 hpi were measured by $\operatorname{TCID}_{50}$ assay. ${ }^{*} P<0.05$ was considered as statistically significant and ${ }^{* *} P<0.01$ was considered as highly significant.

I IFN signaling pathway. To screen the potential proteins that were targeted by EGR1, HEK293T cells were co-transfected with the Myc-Vector or Myc-tagged EGR1 plasmids and the indicated plasmids expressing RIG-I, RIG-I(CARD) (the CARD domain of RIG-I), MDA5(Helicase) (the Helicase domain of MDA5), VISA, TBK1, IRF3 and IRF7, together with ISRE luciferase reporter plasmid and the internal control plasmid PRL-TK. Luciferase activity was measured at $24 \mathrm{~h}$ after transfection. Overexpression of adaptor proteins RIG-I, RIG-I(CARD), MDA5), VISA, TBK1, IRF3 or IRF7 all activated the ISRE luciferase reporter system, and overexpression of MDA5(Helicase) did not activate the ISRE luciferase reporter system (Figure 4). TBK1 or its upstream proteins (RIG-I, MDA5 and VISA) mediated type I IFN signaling was significantly enhanced by overexpression of EGR1. However, overexpression of EGR1 did not promote IRF3 and IRF7 mediated type I IFN signaling (Figure 4). IRF3 and IRF7 are the downstream proteins of TBK1. Therefore, we speculated that TBK1 or its upstream molecules (RIG-I, MDA5 and VISA) were the target/targets of EGR1 to enhance type I IFN signal transduction.

\section{EGR1 Enhances Type I IFN Signaling During FMDV Infection}

To investigate whether EGR1 interacted with the adaptors of type I IFN pathway, the coimmunoprecipitation assay was performed by co-transfection of the Myc-EGR1 plasmids and the plasmids expressing various HA-tagged adaptors of type I IFN pathway. The transfectants were immunoprecipitated with anti-HA antibodies and subjected to Western blotting analysis. No interaction was observed between EGR1 and the adaptors (Figure 5A). EGR1 enhanced the activation of ISRE luciferase reporter stimulated by TBK1 and its upstream molecules. TBK1 might be a key adaptor to enhance type I IFN signaling. The influence of EGR1 on TBK1 expression and TBK1 phosphorylation levels were evaluated in FMDV-infected cells. PK-15 cells were transfected with $2 \mu \mathrm{g}$ of Myc-EGR1 or its empty vector plasmids. The cells were infected with equal amounts of FMDV at $24 \mathrm{hpt}$ and collected at 0, 6, 12, or $18 \mathrm{hpi}$. Overexpression of EGR1 had no influence on TBK1 expression during FMDV infection. However, it significantly promoted TBK1 phosphorylation levels after FMDV infection comparing with that in the empty vector transfected cells (Figure 5B). The VP1 was used as an indicator of viral replication. Overexpression of EGR1 also resulted in decreased VP1 abundance (Figure 5B). This confirmed that upregulation of EGR1 enhanced type I IFN signaling and suppressed FMDV replication.

\section{EGR1 Inhibits FMDV Replication Independent of Its Transcriptional Activity}

As a transcription factor, the transcriptional activity is significantly involved in the regulatory function of EGR1. 

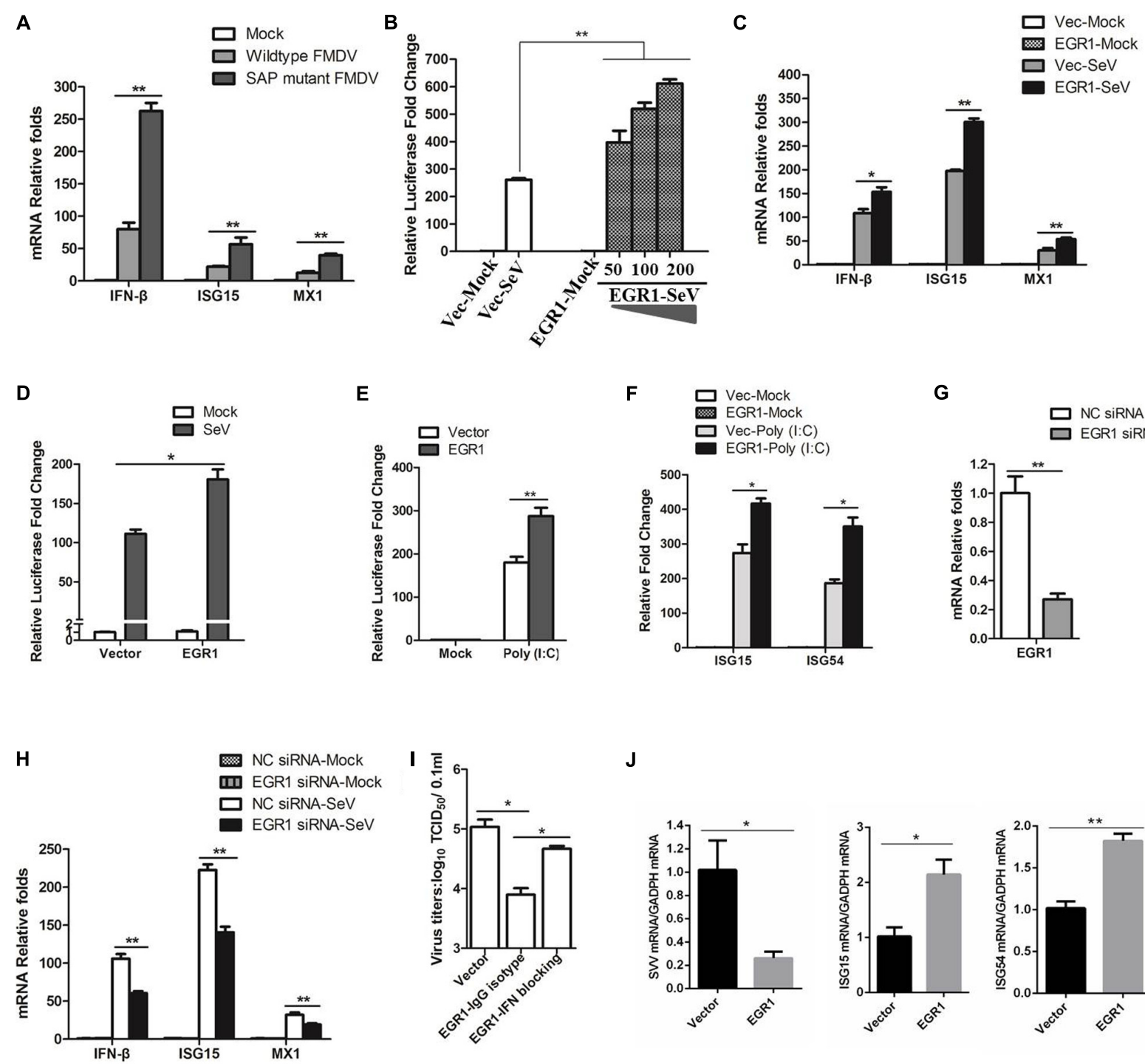

$\mathbf{J}$
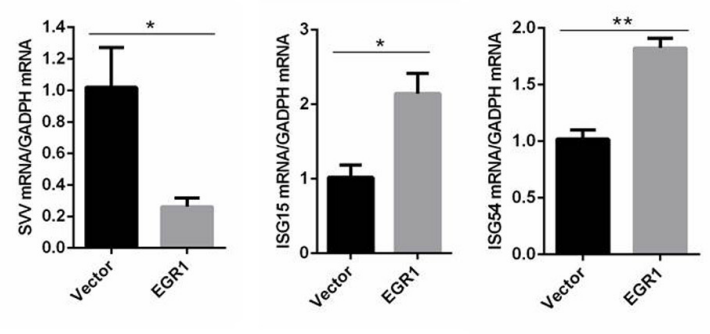

FIGURE 3 | Effect of EGR1 on type I IFN signaling. (A) PK-15 cells were mock-infected or infected with equal amounts of SAP mutant FMDV or wildtype FMDV for $12 \mathrm{~h}$. The transcripts of IFN- $\beta$, ISG15 and MX1 were detected by GPCR. (B) HEK293T cells were transfected with vector plasmids or increasing amounts of Myc-EGR1 plasmids (50, 100, or 200 ng) together with ISRE luciferase reporter plasmid and the internal control plasmid PRL-TK. The transfected cells were infected with SeV at $24 \mathrm{hpt}$ and incubated for $16 \mathrm{~h}$. Dual luciferase assay was then performed according to the Promega Dual-Luciferase Reporter Assay System protocol. (C) HEK293T cells were transfected with vector plasmids or Myc-EGR1 plasmids for $24 \mathrm{~h}$. The transfected cells were mock-infected or infected with SeV for $16 \mathrm{~h}$. The transcripts of IFN- $\beta$, ISG15 and MX1 were detected by GPCR. (D) HEK293T cells were transfected with vector or Myc-EGR1 plasmids together with NF-kB luciferase reporter plasmid and PRL-TK. The transfected cells were infected with SeV, and the luciferase activity was measured by dual luciferase assay. (E) HEK293T cells were transfected with vector plasmids or Myc-EGR1 plasmids and solvent control or Poly (I:C) together with ISRE luciferase reporter plasmid and PRL-TK. The luciferase activity was measured by dual luciferase assay. (F) HEK293T cells were co-transfected with vector plasmids or Myc-EGR1 plasmids and solvent control or Poly (I:C), the expression of ISG15 and ISG54 expression was measured by qPCR. (G) HEK293T cells were transfected with NC or EGR1 siRNA-1819 for $48 \mathrm{~h}$. The EGR1 transcripts were measured by qPCR. (H) HEK293T cells were transfected with NC siRNA or EGR1 siRNA-1819 for $48 \mathrm{~h}$. The cells were then mock-infected or infected with SeV for $16 \mathrm{~h}$. The transcripts of IFN- $\beta$, ISG15 and MX1 were detected by qPCR. (I) PK-15 cells were transfected with equal amounts of vector or EGR1 expressing plasmids for $24 \mathrm{~h}$, the EGR1-transfected cell were mock-treated or treated with IFN antibodies for $1 \mathrm{~h}$ and then infected with FMDV. The viral yields were measured by TCID 50 assay at $12 \mathrm{hpi}$. (J) PK-15 cells were transfected with vector plasmids or Myc-EGR1 plasmids for $24 \mathrm{~h}$. The transfected cells were infected with SW for $12 \mathrm{~h}$. The viral RNA, ISG15 and ISG54 expression levels were detected by qPCR. ${ }^{*} P<0.05$ was considered as statistically significant and ${ }^{* *} P<0.01$ was considered as highly significant.

To investigate whether the transcriptional activity is related to the antiviral function of EGR1, ZnEgr1, a previous reported dominant-negative mutant of EGR1 that lacks a transcriptional function, was used as an inhibitor of the transcriptional activity of EGR1 (Levkovitz and Baraban, 2001). The Myc-tagged ZnEGR1 expressing plasmid was constructed (Figure 6A). PK-15 cells were transfected with vector, Myc-EGR1 plasmids or cotransfected with Myc-EGR1 and Myc-ZnEGR1 

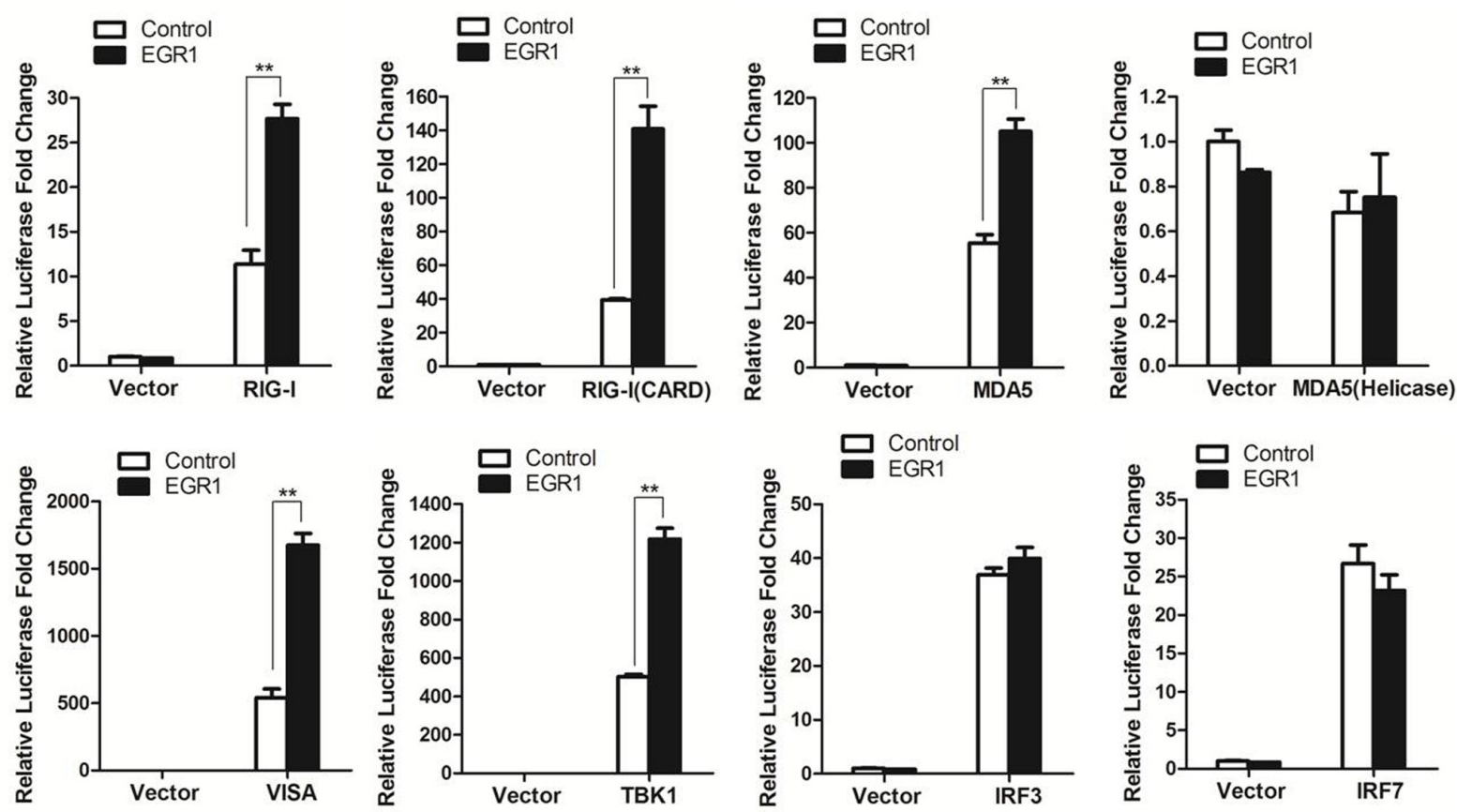

FIGURE 4 | The target of EGR1 in type I IFN pathway activation. HEK293T cells were co-transfected with Myc-EGR1 or empty vector plasmids and the constructs expressing RIG-I, RIG-I(CARD), MDA5, VISA, TBK1, IRF3 or IRF7, together with ISRE luciferase reporter plasmid and the internal control plasmid PRL-TK. Dual luciferase activity was determined at $24 \mathrm{hpt} .{ }^{* *} P<0.01$ was considered as highly significant.
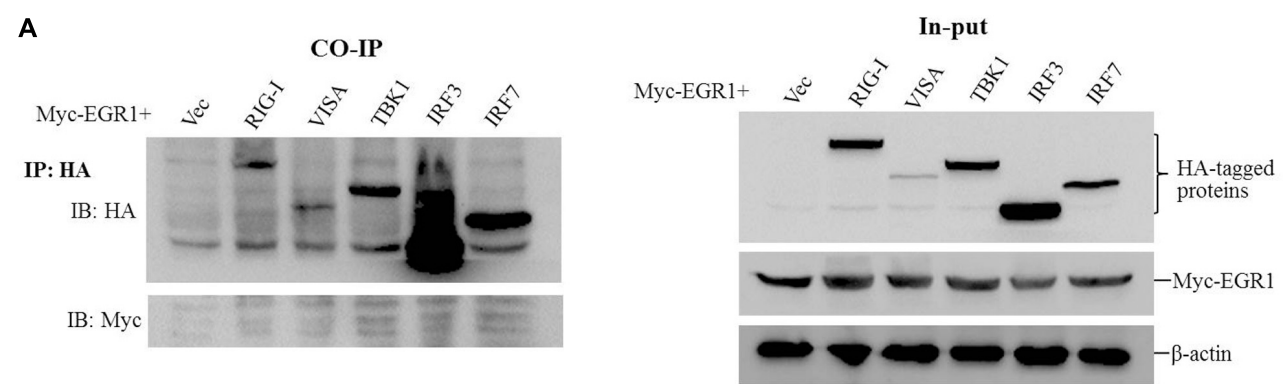

B

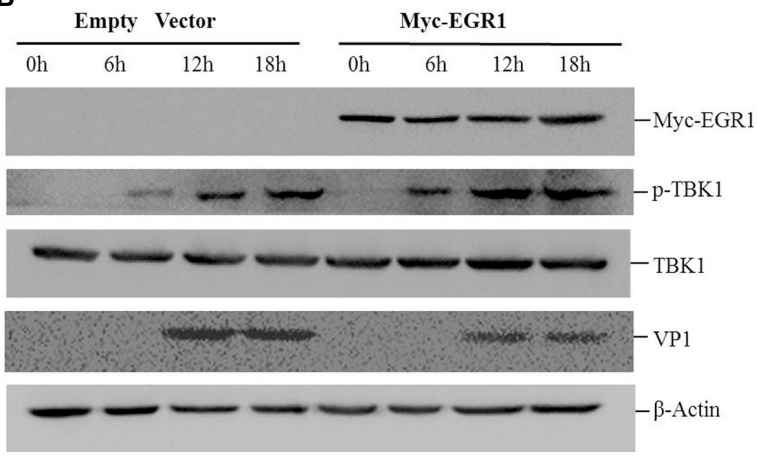

FIGURE 5 | EGR1 enhances type I IFN pathway activation during FMDV infection. (A) HEK293T cells were co-transfected with Myc-EGR1 and HA-RIG-I, HA-VISA, HA-TBK1, HA-IRF3 or HA-IRF7 for $36 \mathrm{~h}$. The transfects were immunoprecipitated with anti-HA antibodies and subjected to Western blotting analysis. Input represents the whole cell lysates. (B) PK-15 cells were transfected with $2 \mu \mathrm{g}$ of empty vector or Myc-EGR1 expressing plasmids. The cells were infected with equal amounts of FMDV at $24 \mathrm{hpt}$. The infected cells were collected at 0, 6, 12, or $18 \mathrm{hpi}$ and subjected to Western blotting analysis. The expression of Myc-EGR1, p-TBK1 (phosphorylated TBK1), TBK1, VP1 and $\beta$-Actin were detected. 
A

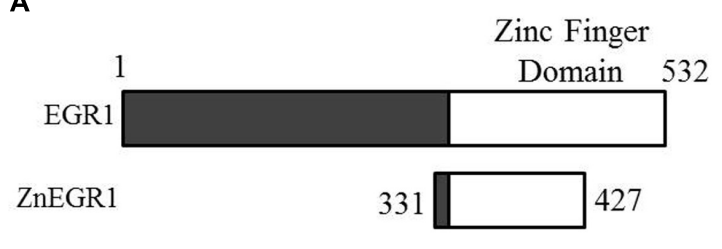

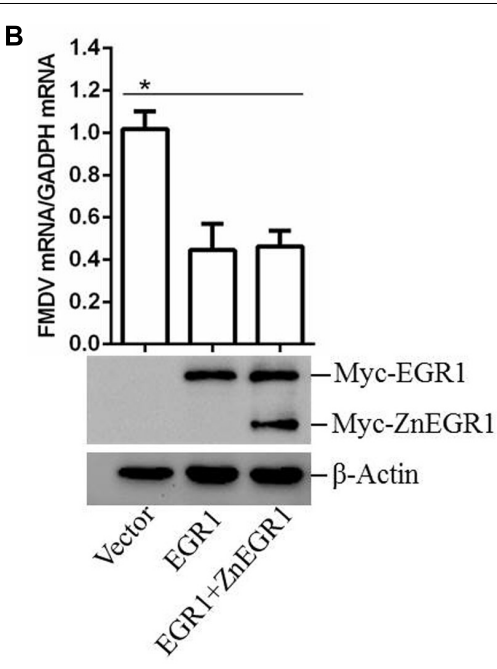

C
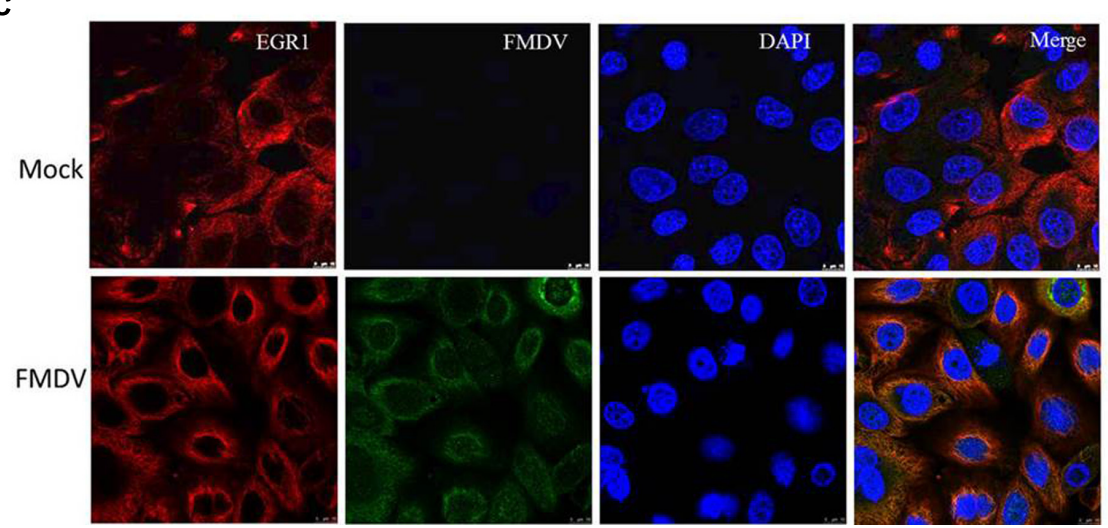

FIGURE 6 | EGR1 suppresses FMDV replication independent of its transcriptional activity. (A) Schematic diagram of the wildtype EGR1 and ZnEGR1. (B) PK-15 cells were transfected with vector, Myc-EGR1 plasmids or cotransfected with Myc-EGR1 and Myc-ZnEGR1 plasmids and subjected to FMDV infection. The expression of Myc-EGR1 and Myc-ZnEGR1 was detected by Western blotting. FMDV RNA was detected by qPCR. (C) PK-15 cells were mock-infected or infected with FMDV for $12 \mathrm{~h}$; the localization of EGR1 was detected by indirect fluorescence assay. ${ }^{*} P<0.05$ was considered as statistically significant.

plasmids and subjected to FMDV infection. Overexpression of EGR1 suppressed FMDV replication, and EGR1-mediated antiviral effect was not blocked by cotransfection with ZnEgr1 (Figure 6B). We further evaluated the localization of EGR1 in mock- or FMDV-infected cells, and we found FMDV infection did not change the localization of EGR1 compared with that in the mock-infected cells (Figure 6C). These data suggest that the transcriptional activity is not involved in the antiviral function of EGR1.

\section{DISCUSSION}

EGR1, as a multifunctional transcription factor, plays regulatory roles in a variety of cellular responses. In addition, EGR1 shows an anti-tumor function. Overexpression of EGR1 decreases tumorigenesis in nude mice and various of human tumor cell lines (Huang et al., 1994, 1995). Induction of TGF $\beta 1$ and p53 may lead to the tumor suppressor property of EGR1 (Baron et al., 2006). p53, as a tumor suppressor, has also been implicated in other functions that play important roles in disease and health (Fuhrman et al., 2009). p53-dependent antiviral defense has been widely reported (Takaoka et al., 2003; Shin-Ya et al., 2005; MuñozFontela et al., 2008). Such as, p53 serves as an antiviral protein during influenza A virus infection by enhancing host innate and adaptive immune responses (Muñoz-Fontela et al., 2011). EGR1 directly induces the transcription of p53 (Liu et al., 2004), whether EGR1 is also involved in host antiviral responses remains unknown. In this study, we determined that EGR1 revealed an antiviral function against FMDV, which indicated that EGR1 is implicated in host antiviral response.

EGR1 can be upregulated upon viral infection by Epstein-Barr virus, mouse hepatitis virus (MHV), VEEV, EV71, rabies viruses and Japanese encephalitis virus infections (Saha and Rangarajan, 2003; Cai et al., 2006; Kim et al., 2013; Song et al., 2015; Baer et al., 2016). However, EGR1 expression is related to viral pathogenesis during VEEV, MHV and EV71 replication. All these studies were performed using mouse or human cells, and most of these viruses can cause central nervous system (CNS) diseases. In this study we investigated the function of porcine EGR1 and showed the 
antiviral role of porcine EGR1 against FMDV. FMDV infection does not cause any CNS disease. Whether the difference of species or tissue tropism resulted in the different role of EGR1 in different virus infections remain unknown. However, EGR1 has been suggested to participate in IFN- $\gamma$-STAT1 pathway in T cells (Shin et al., 2009). T-bet is a Th1-specific transcription factor that is directly involved in T cells differentiation (Djuretic et al., 2007). EGR1 regulates T-bet expression by binding to the promoter of T-bet and induces T-bet transcription (Shin et al., 2009). T-bet plays a vital role in innate immunity, and lacking of T-bet expression increases host susceptibility to inflammatory disease (Garrett et al., 2007). This implies a regulatory role of EGR1 in innate immunity. Besides, overexpression of EGR1 downregulates NFKB inhibitor (Kim et al., 2013), which also implies a potential role of EGR1 in innate immunity.

In this study, we determined that EGR1 is implicated in innate immunity during FMDV infection. A higher EGR1 expression was observed in SAP mutant FMDV-infected cells comparing with that in the wildtype FMDV-infected cells. It has been determined that SAP mutant FMDV infection resulted in stronger type I IFN signaling than wildtype FMDV infection (de los Santos et al., 2009). We found that SAP mutant FMDV infection triggered higher expression of IFN- $\beta$ and ISGs than wildtype FMDV infection. This result was similar as the result reported by de los Santos et al. (2009) previously. Whether the higher expression of EGR1 correlated with the higher expression of IFN- $\beta$ and ISGs was therefore investigated. Overexpression of EGR1 significantly activated type I IFN signaling and IFN- $\beta$ and ISGs expression. Knockdown of EGR1 considerably impaired SeV-induced IFN- $\beta$ and ISGs expression. Type I IFN blocking antibodies obviously abrogated the inhibitory effects of EGR1 on FMDV propagation. This suggested EGR1 is implicated in type I IFN pathway activation. A link between EGR1 and type I IFN pathway was reported for the first time.

Further investigation of EGR1-mediated enhancive effect showed that EGR1 promoted activation of the type I IFN signaling during FMDV infection. Overexpression of EGR1 upregulated TBK1 phosphorylation during FMDV infection. TBK1 phosphorylation enhanced type I IFN signaling and strengthened antiviral activity which subsequently suppressed FMDV replication. EGR1 is a transcription factor; however, it does not induce TBK1 expression. The interaction between EGR1 and various adaptors of type I IFN signaling pathway was not observed by performing coimmunoprecipitation assay.

\section{REFERENCES}

Baer, A., Lundberg, L., Swales, D., Waybright, N., Pinkham, C., Dinman, J. D., et al. (2016). Venezuelan Equine encephalitis virus induces apoptosis through the unfolded protein response activation of EGR1. J. Virol. 90, 3558-3572. doi: 10.1128/JVI.02827-15

Baron, V., Adamson, E. D., Calogero, A., Ragona, G., and Dan, M. (2006). The transcription factor Egr1 is a direct regulator of multiple tumor suppressors including TGF $\beta 1$, PTEN, p53 and fibronectin: Egr1 is a potential target of gene therapy for prostate cancer. Cancer Gene Ther. 13, 115-124. doi: 10.1038/sj.cgt. 7700896
The role of the transcriptional activity of EGR1 for its antiviral function against FMDV was also evaluated. Suppression of the transcriptional activity of EGR1 did not affect its antiviral effect. EGR1 might enhance type I IFN signaling independent of its transcriptional activity. How does EGR1 promote TBK1 phosphorylation is not clear. Several phosphatases have been identified as regulator of phosphorylation of TBK1 (Gabhann et al., 2010; Zhao, 2013). The regulation of EGR1 on these phosphatases should be studied in future, and the detailed mechanism of EGR1 to promote TBK1 phosphorylation should be further investigated. In addition, the effect of EGR1 on the adaption of other upstream molecules of TBK1 should also be exploited.

\section{CONCLUSION}

In summary, we present the first investigation of EGR1 in regulation of type I IFN signaling during FMDV infection. We determined that EGR1 showed an antiviral function against FMDV. EGR1 promoted activation of the type I IFN signaling during FMDV infection and resulted in the decreased replication of FMDV. EGR1 suppressed FMDV replication independent of its transcriptional activity. These findings identify an important role of EGR1 in enhancement of type I IFN signaling during FMDV infection. However, the exact mechanism for EGR1 to promote type I IFN signaling should be investigated in future to gain deeper understanding of EGR1-mediated functions.

\section{AUTHOR CONTRIBUTIONS}

$\mathrm{ZZ}, \mathrm{XD}$, and $\mathrm{HZ}$ conceived the study and wrote the manuscript. $\mathrm{ZZ}, \mathrm{XD}, \mathrm{PL}, \mathrm{XZ}, \mathrm{FY}$, and WC performed the experiments. HT, $\mathrm{KZ}$, and XL collected the data, analyzed the data, and revised the manuscript.

\section{FUNDING}

This work was supported by grants from the Gansu Science Foundation for Distinguished Young Scholars (1606RJDA313), National Natural Sciences Foundation of China (Nos. U1501213 and 31672585), and the Key Development and Research Foundation of Yunnan (2018BB004). 
Cai, Y., Liu, Y., and Zhang, X. (2006). Induction of transcription factor Egr-1 gene expression in astrocytoma cells by Murine coronavirus infection. Virology 355, 152-163. doi: 10.1016/j.virol.2006.07.012

Cubero, F. J., and Nieto, N. (2012). Arachidonic acid stimulates TNF $\alpha$ production in kupffer cells via a reactive oxygen species-pERK1/2-Egr1-dependent mechanism. Am. J. Physiol. Gastrointest. Liver Physiol. 303, 228-239. doi: 10. 1152/ajpgi.00465.2011

de los Santos, T., Diaz-San Segundo, F., Zhu, J., Koster, M., Dias, C. C., and Grubman, M. J. (2009). A conserved domain in the leader proteinase of footand-mouth disease virus is required for proper subcellular localization and function. J. Virol. 83, 1800-1810. doi: 10.1128/JVI.02112-08

Diaz-San Segundo, F., Weiss, M., Perez-Martin, E., Dias, C. C., Grubman, M. J., and De Los Santos, T. (2012). Inoculation of swine with foot-and-mouth disease SAP-mutant virus induces early protection against disease. J. Virol. 86, 1316-1327. doi: 10.1128/JVI.05941-11

Djuretic, I. M., Levanon, D., Negreanu, V., Groner, Y., Rao, A., and Ansel, K. M. (2007). Transcription factors T-bet and Runx3 cooperate to activate Ifng and silence Il4 in T helper type 1 cells. Nat. Immunol. 8, 145-153. doi: 10.1038/ ni1424

Domingo, E., Pariente, N., Airaksinen, A., Gonzalez-Lopez, C., Sierra, S., Herrera, M., et al. (2005). Foot-and-mouth disease virus evolution: exploring pathways towards virus extinction. Curr. Top. Microbiol. Immunol. 288, 149173.

Fuhrman, L. E., Goel, A. K., Smith, J., Shianna, K. V., and Aballay, A. (2009). Nucleolar proteins suppress Caenorhabditis elegans innate immunity by inhibiting p53/CEP-1. PLoS Genet. 5:e1000657. doi: 10.1371/journal.pgen. 1000657

Gabhann, J. N., Higgs, R., Brennan, K., Thomas, W., Damen, J. E., Ben Larbi, N., et al. (2010). Absence of SHIP-1 results in constitutive phosphorylation of tank-binding kinase 1 and enhanced TLR3-dependent IFN-beta production. J. Immunol. 184, 2314-2320. doi: 10.4049/jimmunol.0902589

Garrett, W. S., Lord, G. M., Punit, S., Lugo-Villarino, G., Mazmanian, S. K., Ito, S., et al. (2007). Communicable ulcerative colitis induced by T-bet deficiency in the innate immune system. Cell 131, 33-45. doi: 10.1016/j.cell.2007.08.017

Grubman, M. J., and Baxt, B. (2004). Foot-and-mouth disease. Clin. Microbiol. Rev. 17, 465-493. doi: 10.1128/CMR.17.2.465-493.2004

Huang, R. P., Darland, T., Okamura, D., Mercola, D., and Adamson, E. D. (1994). Suppression of $\mathrm{v}$-sis-dependent transformation by the transcription factor, Egr-1. Oncogene 9, 1367-1377.

Huang, R. P., Liu, C., Fan, Y., Mercola, D., and Adamson, E. D. (1995). Egr-1 negatively regulates human tumor cell growth via the DNA-binding domain. Cancer Res. 55, 5054-5062.

Jo, G., Shin, S. Y., Lee, Y., Hyun, J., Dong, K. S., Park, J. C., et al. (2011). A compound isolated from Rumex japonicus induces early growth response gene-I expression. J. Korean Soc. Appl. Biol. Chem. 54, 637-643.

Khachigian, L. M., Anderson, K. R., Halnon, N. J., Gimbrone, M. A., Resnick, N., and Collins, T. (1997). Egr-1 is activated in endothelial cells exposed to fluid shear stress and interacts with a novel shear-stress-response element in the PDGF a-chain promoter. Arterioscler. Thromb. Vasc. Biol. 17, 2280-2286. doi: 10.1161/01.ATV.17.10.2280

Kim, J. H., Kim, W. S., and Park, C. (2013). Epsteinâ-Barr virus latent membrane protein 1 increases genomic instability through Egr-1-mediated upregulation of activation-induced cytidine deaminase in B-cell lymphoma. Leuk. Lymphoma 54, 2035-2040. doi: 10.3109/10428194.2013.769218

Levkovitz, Y., and Baraban, J. M. (2001). A dominant negative inhibitor of the Egr family of transcription regulatory factors suppresses cerebellar granule cell apoptosis by blocking c-Jun activation. J. Neurosci. 21, 5893-5901. doi: 10.1523/ JNEUROSCI.21-16-05893.2001

Li, D., Yang, W., Yang, F., Liu, H., Zhu, Z., Lian, K., et al. (2016). The VP3 structural protein of foot-and-mouth disease virus inhibits the IFN- $\beta$ signaling pathway. FASEB J. 30, 1757-1766. doi: 10.1096/fj.15-281410

Li, W., Zhu, Z., Cao, W., Yang, F., Zhang, X., Li, D., et al. (2016). Esterase D enhances type I interferon signal transduction to suppress foot-and-mouth disease virus replication. Mol. Immunol. 75, 112-121. doi: 10.1016/j.molimm. 2016.05.016

Li, D. P., Ilnytskyy, Y., Kovalchuk, A., Khachigian, L. M., Bronson, R. T., Wang, B., et al. (2013). Crucial role for early growth response- 1 in the transcriptional regulation of miR-20b in breast cancer. Oncotarget 4, 1373-1387. doi: 10.18632/ oncotarget.1165

Liu, J., Grogan, L., Nau, M. M., Allegra, C. J., Chu, E., and Wright, J. J. (2004). Physical interaction between p53 and primary response gene Egr-1. Henan Med. Res. 18, 863-870.

Mason, P. W., Grubman, M. J., and Baxt, B. (2003). Molecular basis of pathogenesis of FMDV. Virus Res. 91, 9-32. doi: 10.1016/S0168-1702(02)00257-5

McMahon, S. B., and Monroe, J. G. (1996). The role of early growth response gene 1 (egr-1) in regulation of the immune response. J. Leukoc. Biol. 60, 159-166. doi: $10.1002 /$ jlb.60.2.159

Muñoz-Fontela, C., Macip, S., Martínez-Sobrido, L., Brown, L., Ashour, J., García-Sastre, A., et al. (2008). Transcriptional role of p53 in interferonmediated antiviral immunity. J. Exp. Med. 205, 1929-1938. doi: 10.1084/jem. 20080383

Muñoz-Fontela, C., Pazos, M., Delgado, I., Murk, W., Mungamuri, S. K., Lee, S. W., et al. (2011). p53 serves as a host antiviral factor that enhances innate and adaptive immune responses to influenza A virus. J. Immunol. 187, 6428-6436. doi: 10.4049/jimmunol.1101459

Nishi, H., Nishi, K. H., and Johnson, A. C. (2002). Early growth response-1 gene mediates up-regulation of epidermal growth factor receptor expression during hypoxia. Cancer Res. 62, 827-834.

Pagel, J. I., and Deindl, E. (2011). Early growth response 1-a transcription factor in the crossfire of signal transduction cascades. Indian J. Biochem. Biophys. 48, 226-235.

Papanikolaou, N. A., Tillinger, A., Liu, X., Papavassiliou, A. G., and Sabban, E. L. (2014). A systems approach identifies co-signaling molecules of early growth response 1 transcription factor in immobilization stress. BMC Syst. Biol. 8:100. doi: 10.1186/s12918-014-0100-8

Paton, D. J., and Taylor, G. (2011). Developing vaccines against foot-and-mouth disease and some other exotic viral diseases of livestock. Philos. Trans. R. Soc. B Biol. Sci. 366, 2774-2781. doi: 10.1098/rstb.2011.0107

Rodriguez Pulido, M., and Saiz, M. (2017). Molecular mechanisms of foot-andmouth disease virus targeting the host antiviral response. Front. Cell. Infect. Microbiol. 7:252. doi: 10.3389/fcimb.2017.00252

Rweyemamu, M., Roeder, P., Mackay, D., Sumption, K., Brownlie, J., Leforban, Y., et al. (2008a). Epidemiological patterns of foot-and-mouth disease worldwide. Transbound. Emerg. Dis. 55, 57-72. doi: 10.1111/j.1865-1682.2007. 01013.x

Rweyemamu, M., Roeder, P., Mackay, D., Sumption, K., Brownlie, J., and Leforban, Y. (2008b). Planning for the progressive control of foot-and-mouth disease worldwide. Transbound. Emerg. Dis. 55, 73-87. doi: 10.1111/j.18651682.2007.01016.x

Saha, S., and Rangarajan, P. N. (2003). Common host genes are activated in mouse brain by Japanese encephalitis and rabies viruses. J. Gen. Virol. 84, 1729-1735. doi: 10.1099/vir.0.18826-0

Shin, H. J., Lee, J. B., Park, S. H., Chang, J., and Lee, C. W. (2009). T-bet expression is regulated by EGR1-mediated signaling in activated T cells. Clin. Immunol. 131, 385-394. doi: 10.1016/j.clim.2009.02.009

Shin-Ya, M., Hirai, H., Satoh, E., Kishida, T., Asada, H., Aoki, F., et al. (2005). Intracellular interferon triggers jak/stat signaling cascade and induces p53-dependent antiviral protection. Biochem. Biophys. Res. Commun. 329, 1139-1146. doi: 10.1016/j.bbrc.2005.02.088

Skerka, C., Decker, E. L., and Zipfel, P. F. (1995). A regulatory element in the human interleukin 2 gene promoter is a binding site for the zinc finger proteins Sp1 and EGR-1. J. Biol. Chem. 270, 22500-22506. doi: 10.1074/jbc.270.38. 22500

Sobrino, F., and Domingo, E. (2001). Foot-and-mouth disease in Europe. FMD is economically the most important disease of farm animals. Its re-emergence in Europe is likely to have consequences that go beyond severe alterations of livestock production and trade. EMBO Rep. 2, 459-461. doi: 10.1093/emboreports/kve122

Song, Y., Cheng, X., Yang, X., Zhao, R., Wang, P., Han, Y., et al. (2015). Early growth response-1 facilitates enterovirus 71 replication by direct binding to the viral genome RNA. Int. J. Biochem. Cell Biol. 62, 36-46. doi: 10.1016/j.biocel. 2015.02.012

Takaoka, A., Hayakawa, S., Yanai, H., Stoiber, D., Negishi, H., Kikuchi, H., et al. (2003). Integration of interferon- $|\alpha| /|\beta|$ signalling to p53 responses in 
tumour suppression and antiviral defence. Nature 424, 516-523. doi: 10.1038/ nature 01850

Trottier, C., Colombo, M., Mann, K. K., Miller, W. H. Jr., and Ward, B. J. (2009). Retinoids inhibit measles virus through a type I IFN-dependent bystander effect. FASEB J. 23, 3203-3212. doi: 10.1096/fj.09-129288

Zai-Xin, L. (2015). Progress and prospect of the technologies to control foot-andmouth disease and its pathogen characteristics worldwide. Sci. Agric. Sin. 48, 3547-3564.

Zhao, W. (2013). Negative regulation of TBK1-mediated antiviral immunity. FEBS Lett. 587, 542-548. doi: 10.1016/j.febslet.2013.01.052

Zheng, H. X., He, J. J., Guo, J. H., Jin, Y., Yang, F., Lv, L., et al. (2012). Genetic characterization of a new pandemic Southeast Asia topotype strain of serotype O foot-and-mouth disease virus isolated in China during 2010. Virus Genes 44, 80-88. doi: 10.1007/s11262-011-0670-0

Zhou, Q., Lin, H., Wang, S., Wang, S., Ran, Y., Liu, Y., et al. (2014). The ERassociated protein $\mathrm{ZDHHC1}$ is a positive regulator of DNA virus-triggered, MITA/STING-dependent innate immune signaling. Cell Host Microbe 16, 450-461. doi: 10.1016/j.chom.2014.09.006

Zhu, Z., Shi, Z., Yan, W., Wei, J., Shao, D., Deng, X., et al. (2013). Nonstructural protein 1 of influenza A virus interacts with human guanylate-binding protein 1 to antagonize antiviral activity. PLoS One 8:e55920. doi: 10.1371/journal.pone. 0055920
Zhu, Z., Wang, G., Yang, F., Cao, W., Mao, R., Du, X., et al. (2016). Foot-andmouth disease virus viroporin $2 \mathrm{~B}$ antagonizes RIG-I mediated antiviral effects by inhibition of its protein expression. J. Virol. 90, 11106-11121. doi: 10.1128/ JVI.01310-16

Zhu, Z., Yang, F., Zhang, K., Cao, W., Jin, Y., Wang, G., et al. (2015). Comparative proteomic analysis of wild-type and SAP domain mutant foot-and-mouth disease virus-infected porcine cells identifies the ubiquitin-activating enzyme UBE1 required for virus replication. J. Proteome Res. 14, 4194-4206. doi: 10. 1021/acs.jproteome.5b00310

Conflict of Interest Statement: The authors declare that the research was conducted in the absence of any commercial or financial relationships that could be construed as a potential conflict of interest.

Copyright (C) $2018 \mathrm{Zhu}, \mathrm{Du}, \mathrm{Li}$, Zhang, Yang, Cao, Tian, Zhang, Liu and Zheng. This is an open-access article distributed under the terms of the Creative Commons Attribution License (CC BY). The use, distribution or reproduction in other forums is permitted, provided the original author(s) and the copyright owner(s) are credited and that the original publication in this journal is cited, in accordance with accepted academic practice. No use, distribution or reproduction is permitted which does not comply with these terms. 